\title{
Seeking the unseen: Localization and surgery for an occult sporadic insulinoma
}

\author{
Duminda Subasinghe ${ }^{1,2}$, Sonali Sihindi Chapa Gunatilake ${ }^{3}$, Vihara Erangika Dassanyake $e^{1,2}$, \\ Chaminda Garusinghe ${ }^{3}$, Eranga Ganewaththa ${ }^{4}$, Chinthaka Appuhamy ${ }^{4}$, Noel P. Somasundaram ${ }^{3}$, \\ and Sivasuriya Sivaganesh ${ }^{1,2}$
}

\author{
${ }^{1}$ Division of HPB Surgery, Department of Surgery, Faculty of Medicine, University of Colombo, \\ ${ }^{2}$ The University Surgical Unit, The National Hospital of Sri Lanka, Departments of ${ }^{3}$ Endocrinology and Diabetes and \\ ${ }^{4}$ Interventional Radiology, The National Hospital of Sri Lanka, Colombo, Sri Lanka
}

\begin{abstract}
Insulinomas are rare pancreatic neuroendocrine tumours and the commonest cause for endogenous hyperinsulinaemic hypoglycemia. Small tumours are not easily detected by conventional cross-sectional imaging making localization prior to surgical removal a challenge. Selective arterial calcium stimulation is an invaluable adjunct to localization in such circumstances. This is further supplemented by intraoperative ultrasonography. A 39-year-old male was referred with features of Whipple's triad of 10 months duration. Clinical and biochemical evaluation including C-peptide and serum insulin levels during supervised hypoglycemia concluded endogenous hyperinsulinaemia as the underlying aetiology. Contrast CT and MRI of the abdomen failed to localize the tumour. Selective arterial calcium stimulation localized the lesion in distal pancreas. During the surgery, tumour was further localized to the tail of the pancreas using intraoperative ultrasonography and enucleated. Histology confirmed an insulinoma and patient made an unremarkable recovery and was well more than a year after the surgery. (Ann Hepatobiliary Pancreat Surg 2020;24:234-238)
\end{abstract}

Key Words: Insulinoma; Selective arterial calcium stimulation; Enucleation

\section{INTRODUCTION}

Insulinomas are rare but the commonest among pancreatic neuroendocrine tumours (pNET). ${ }^{1}$ Most are intrapancreatic, benign and solitary and have an excellent prognosis after surgical removal. The majority are $<2 \mathrm{~cm}$ in size and distributed equally in the head, body and tail of the pancreas. ${ }^{2}$ Thus, preoperative localization is key to planning surgery. This will prevent prolonged intraoperative attempts to locate and at worst failure to remove the lesion despite laparotomy. Techniques used in preoperative localization include transabdominal ultrasonography, contrast enhanced computed tomography (CECT), magnetic resonance imaging (MRI), endoscopic ultrasonography (EUS) and selective arterial calcium stimulation with hepatic venous sampling. ${ }^{2}$ We present a patient with endogenous hyperinsulinaemic hypoglycaemia in whom success- ful localization was achieved with selective arterial calcium stimulation (SACS) with hepatic venous sampling and intra-operative ultrasonography (IOUS) after cross sectional imaging failed to localize the lesion. To our knowledge, this is the first such report from Sri Lanka and highlights the benefits of harnessing multidisciplinary expertise to achieve optimal outcomes in challenging cases.

\section{CASE}

A 39-year-old male was evaluated for clinical features of hypoglycaemia of 10 months. These episodes corresponded with low capillary blood glucose (CBG) assays of up to $46 \mathrm{mg} / \mathrm{dl}$ and fulfilled Whipple's triad. He had an otherwise normal premorbid status and clinical examination was unremarkable. A supervised 72-hour fast combined with CBG $(31 \mathrm{mg} / \mathrm{dl})$ serum insulin $(71.28 \mathrm{pmol} / \mathrm{L}$

Received: October 23, 2019; Revised: February 17, 2020; Accepted: March 4, 2020

Corresponding author: Duminda Subasinghe

Division of HPB Surgery, Department of Surgery, Faculty of Medicine, University of Colombo, No. 25, P.O. Box 271, Kynsey Road, Colombo 00800, Sri Lanka

Tel: +94-716-862-656, Fax: +94-112-671-846, E-mail: dumindas1982@yahoo.com

Copyright (C) 2020 by The Korean Association of Hepato-Biliary-Pancreatic Surgery

This is an Open Access article distributed under the terms of the Creative Commons Attribution Non-Commercial License (http://creativecommons.org/ licenses/by-nc/4.0) which permits unrestricted non-commercial use, distribution, and reproduction in any medium, provided the original work is properly cited. Annals of Hepato-Biliary-Pancreatic Surgery • pISSN: 2508-5778 - elSSN: 2508-5859 
[normal $<21 \mathrm{pmol} / \mathrm{L}])$ and C-peptide level $(2.57 \mathrm{nmol} / \mathrm{L}$ [normal $<0.2 \mathrm{nmol} / \mathrm{L}]$ ) and negative sulfonylurea test confirmed endogenous insulin dependent hypoglycaemia. Multiple endocrine neoplasia I (MEN I) syndrome screening was negative.

Contrast enhanced CT abdomen in the early arterial phase and MRI with gadolinium contrast failed to demonstrate a pancreatic lesion (Fig. 1). SACS was performed as per standard protocol. ${ }^{3}$ In brief, selective cannulation and calcium injection into arteries supplying segments of the pancreas was performed. Insulin assays were performed on pre and post calcium infusion catheter samples obtained from the hepatic veins (Fig. 2). A two-fold rise in

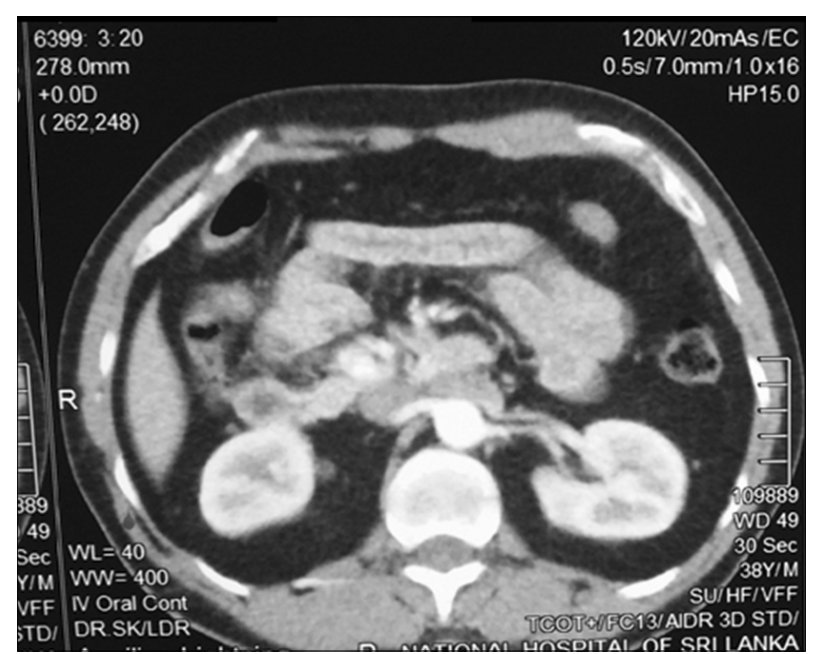

Fig. 1. CECT abdomen showing normal pancreas.

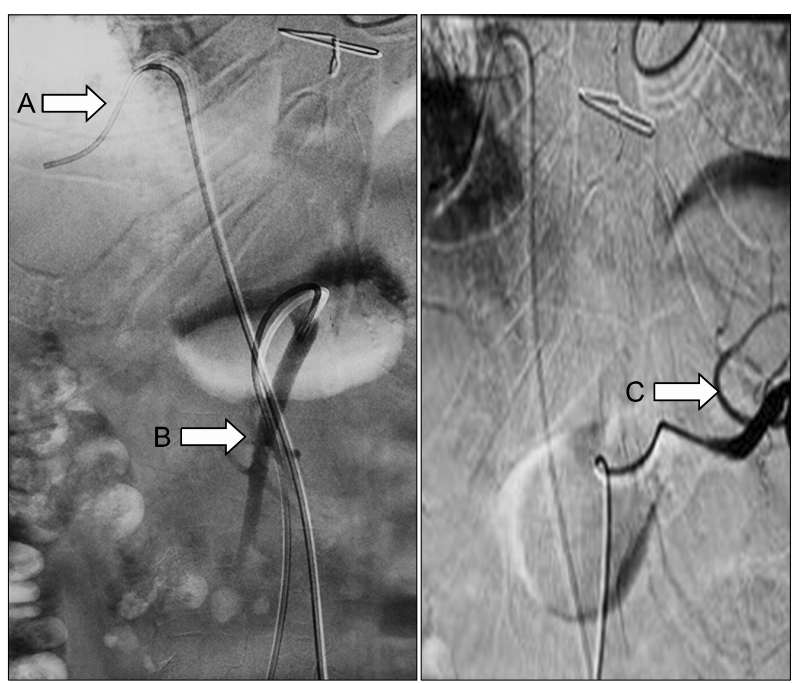

Fig. 2. Selective arterial calcium stimulation; (A) Catheter in hepatic vein, (B) Superior mesenteric artery, (C) Splenic artery. insulin levels above the baseline was observed in the proximal and distal splenic artery branches, localizing the tumour to the distal body or tail of the pancreas (Fig. 3, Table 1).

Surgery was performed through a bilateral subcostal incision. The pancreatic body and tail were mobilized with the spleen but the tumour could not be located by palpation. Intraoperative ultrasonography (IOUS) located a $1.0 \times$ $0.8 \mathrm{~cm}$ tumour in the pancreatic tail adjacent to the splenic hilum and this was enucleated (Fig. 4). IOUS also excluded the presence of multiple tumours (Fig. 5). Histology confirmed a WHO grade 1 tumour (Ki67 - 1.8\%) pNET or insulinoma (positive staining for NSE). The patient made an uneventful recovery and was normoglycaemic at follow up more than a year later.

\section{DISCUSSION}

Most sporadic insulinomas are solitary and under $2 \mathrm{~cm}$; hence parenchymal sparing complete enucleation is the procedure of choice to minimise morbidity while preventing recurrence. Tumour localization facilitates this and changes in surgical approach if necessary and is an integral part of workup. This case highlights the challenges of pre and intraoperative localization of insulinomas and tools to overcome them.

Cross sectional imaging failed to localise the tumour in this patient. This is not surprising considering that the sen-

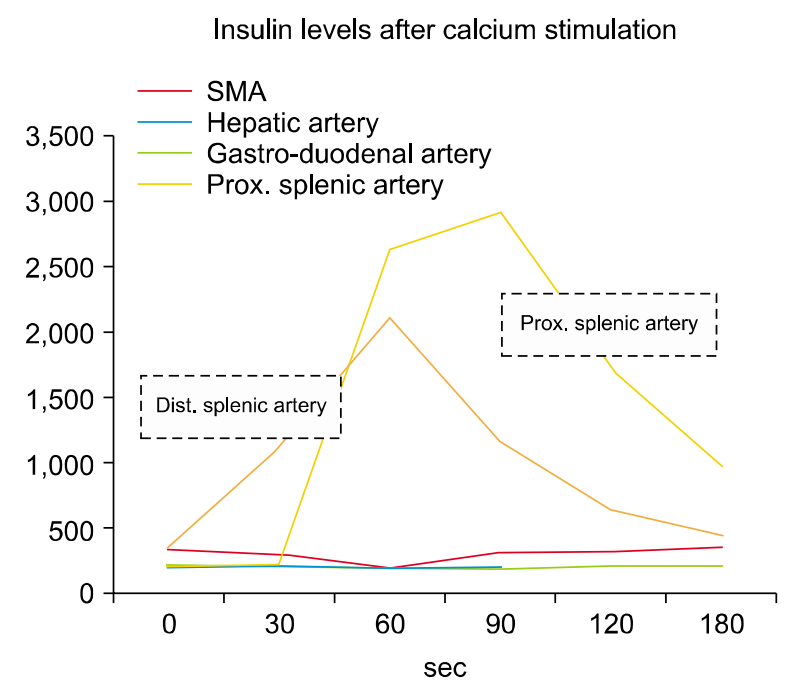

Fig. 3. Insulin levels of arterial territories at selective arterial calcium stimulation test. 
Table 1. Results of selective arterial calcium stimulation test

\begin{tabular}{|c|c|c|c|c|c|}
\hline \multirow{2}{*}{$\begin{array}{l}\text { Time after } \\
\text { calcium injection }\end{array}$} & \multicolumn{5}{|c|}{ Insulin levels (pmol/L) } \\
\hline & $\begin{array}{l}\text { Superior mesenteric } \\
\text { artery }\end{array}$ & $\begin{array}{l}\text { Gastro-duodenal } \\
\text { artery }\end{array}$ & Hepatic artery & Prox. splenic artery & Distal splenic artery \\
\hline $0 \mathrm{sec}$ & 343.0 & 234.43 & 215.16 & 211.75 & 372.22 \\
\hline $30 \mathrm{sec}$ & 308.5 & 216.06 & 222.0 & 237.02 & 1126.22 \\
\hline $60 \mathrm{sec}$ & 206.7 & 205.37 & 194.19 & 2631.18 & 2112.81 \\
\hline $90 \mathrm{sec}$ & 319.3 & 197.92 & 213.15 & 2909.75 & 1164.90 \\
\hline $120 \mathrm{sec}$ & 362.28 & 223.47 & 22.02 & 993.80 & 462.57 \\
\hline
\end{tabular}
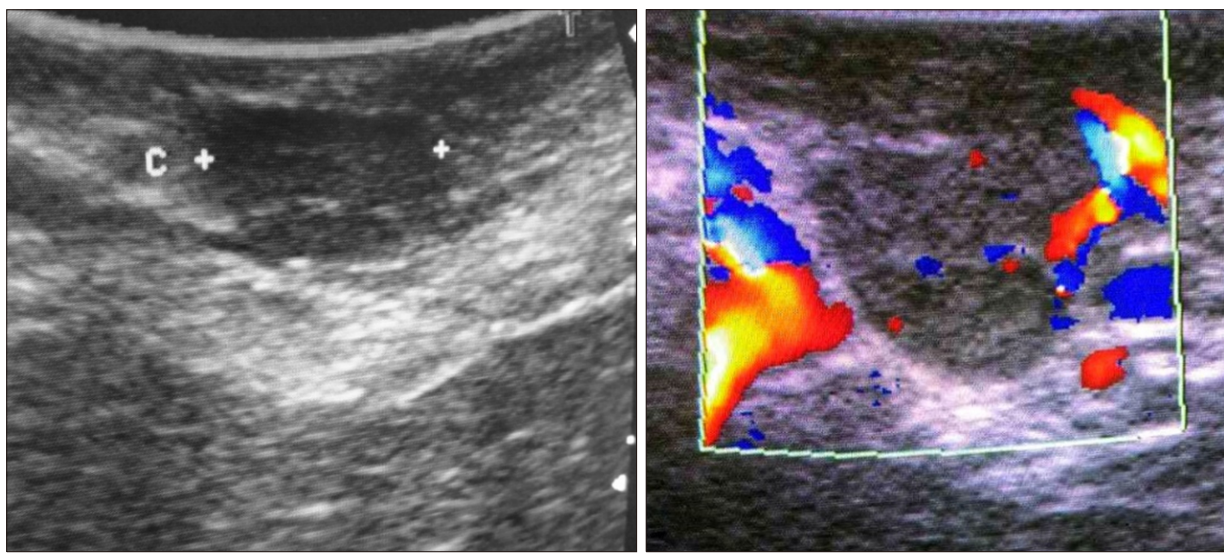

Fig. 4. Insulinoma visualized with intraoperative US combined with Doppler.

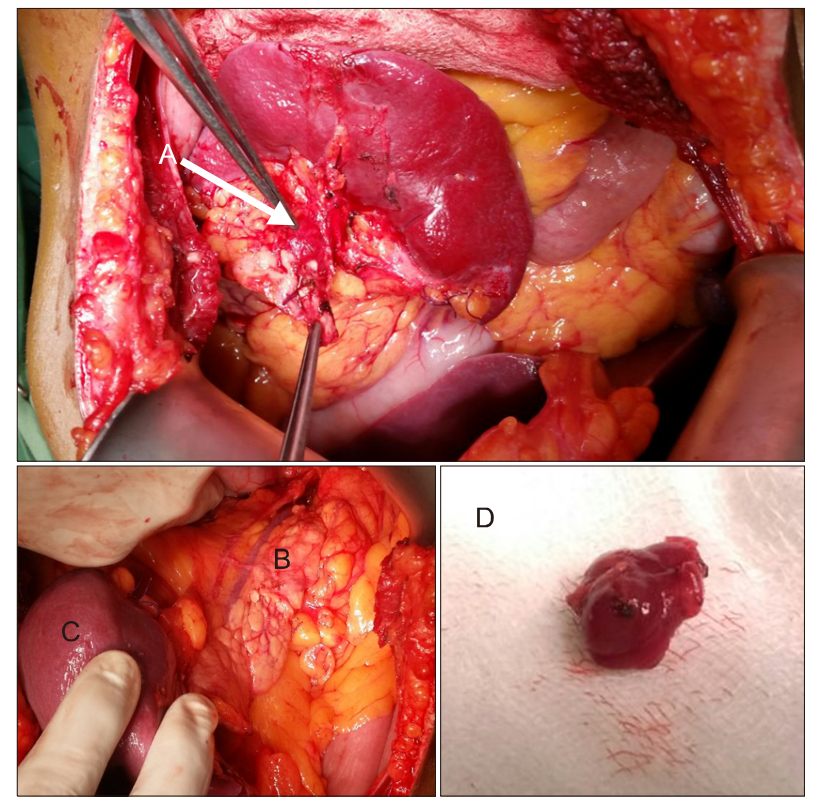

Fig. 5. Intra-operative findings; (A) Insulinoma at the tail of pancreas near splenic hilum, (B) pancreas, (C) Spleen, (D) surgical specimen of enucleated insulinoma.

sitivity of contrast CT and MRI has been reported to range between $33-64 \%$ and $40-90 \%$, respectively. ${ }^{4,5}$ This variability is likely dependent on tumour size, type of machine, protocols used and the expertise of radiologist.
EUS has proven to be a an effective modality in these situations with an overall sensitivity of $80-90 \%$ though this drops sharply for tumours in the tail $(37-50 \%) .{ }^{6,7}$ The lack of available expertise at the time precluded its use in this patient.

SACS is an interventional radiological technique used to preoperatively localize or regionalize occult insulinomas with excellent sensitivity (84-100\%) and specificity (94$100 \%){ }^{8-11}$ Only $20 \%$ of patients who undergo surgical management for insulinoma require preoperative SACS, as the majority are localized with non-invasive imaging. ${ }^{12}$ SACS was developed by Doppman et al..$^{8,13,14}$ in 1989 as a way to localize discrete insulin-secreting islet cell tumours of the pancreas. It is used on the basis that insulinomas have a dominant arterial supply and calcium elicits a unique response on tumour cells causing an insulin surge. ${ }^{14} \mathrm{~A}$ two-fold rise in the insulin levels above the baseline localizes the insulinoma to the anatomic region perfused by the injected artery. Fortunately, this study facilitated localization of the tumour to the distal body or tail in this patient.

Preoperative knowledge of the pancreatic segment containing the insulinoma facilitates directed visual examina- 
tion and palpation to locate the tumour. Despite this, the tumour proved to be elusive and was only located nestled in the tail within the splenic hilum using IOUS. IOUS in combination with intraoperative palpation by an experienced operator has been shown to achieve excellent detection rates of $80-100 \% .{ }^{15,16}$ Recurrence rates for sporadic insulinoma after surgery is $5 \%$ at 10 years and $7 \%$ at 20 years. ${ }^{17}$ Therefore our patients likelihood of recurrence is very low. The patient was well and normoglycaemic more than a year after surgery.

In conclusion, preoperative localization of insulinomas is mandatory to achieve good results with minimum morbidity. SACS is an invaluable adjunct when cross-sectional imaging fails to do this. IOUS, visualization and palpation during surgical exploration compliment preoperative localization. Timely referral to tertiary centres equipped with multidisciplinary expertise improves outcomes.

\section{CONFLICT OF INTEREST}

The authors declare that they have no competing interests.

\section{ORCID}

\author{
Duminda Subasinghe: \\ https://orcid.org/0000-0003-1805-1589 \\ Sonali Sihindi Chapa Gunatilake: \\ https://orcid.org/0000-0003-0636-350X \\ Vihara Erangika Dassanyake: \\ https://orcid.org/0000-0001-6582-0577 \\ Chaminda Garusinghe: \\ https://orcid.org/0000-0001-5432-2038 \\ Eranga Ganewaththa: \\ https://orcid.org/0000-0003-4086-3639 \\ Chinthaka Appuhamy: \\ https://orcid.org/0000-0002-1716-9721 \\ Noel P. Somasundaram: \\ https://orcid.org/0000-0002-6241-7501 \\ Sivasuriya Sivaganesh: \\ https://orcid.org/0000-0002-6874-6904
}

\section{AUTHOR CONTRIBUTIONS}

Conceptualization: DS, SSCG, SS. Data curation: DS,
SSCG. Formal analysis: DS, SSCG, SS. Methodology: DS, SSCG, SS. Project administration: DS, SSCG, VED, CG, EG, CA, NPS, SS. Visualization: DS, SSCG, VED, CG, EG, CA, NPS, SS. Writing - original draft: DS, SSCG. Writing - review \& editing: DS, SSCG, SS.

\section{REFERENCES}

1. Bilimoria KY, Talamonti MS, Tomlinson JS, Stewart AK, Winchester DP, Ko CY, et al. Prognostic score predicting survival after resection of pancreatic neuroendocrine tumors: analysis of 3851 patients. Ann Surg 2008;247:490-500.

2. Abboud B, Boujaoude J. Occult sporadic insulinoma: localization and surgical strategy. World J Gastroenterol 2008;14:657-665.

3. Barts Endocrinology. Barts endocrine e-protocols GI and pancreas [Internet]. London: Barts Endocrinology; 2009 [cited 2012 Oct 20]. Available from: http://bartsendocrinology.co.uk/resources/GI+AND+PANCREAS + and +NETS + PROTOCOLS $+\$ 5 B$ final\$5D.pdf.

4. Sotoudehmanesh R, Hedayat A, Shirazian N, Shahraeeni S, Ainechi S, Zeinali F, et al. Endoscopic ultrasonography (EUS) in the localization of insulinoma. Endocrine 2007;31:238-241.

5. McAuley G, Delaney H, Colville J, Lyburn I, Worsley D, Govender P, et al. Multimodality preoperative imaging of pancreatic insulinomas. Clin Radiol 2005;60:1039-1050.

6. Ardengh JC, Rosenbaum P, Ganc AJ, Goldenberg A, Lobo EJ, Malheiros CA, et al. Role of EUS in the preoperative localization of insulinomas compared with spiral CT. Gastrointest Endosc 2000;51:552-555.

7. Schumacher B, Lübke HJ, Frieling T, Strohmeyer G, Starke AA. Prospective study on the detection of insulinomas by endoscopic ultrasonography. Endoscopy 1996;28:273-276.

8. Doppman JL, Miller DL, Chang R, Shawker TH, Gorden P, Norton JA. Insulinomas: localization with selective intraarterial injection of calcium. Radiology 1991;178:237-241.

9. Brändle M, Pfammatter T, Spinas GA, Lehmann R, Schmid C. Assessment of selective arterial calcium stimulation and hepatic venous sampling to localize insulin-secreting tumours. Clin Endocrinol (Oxf) 2001;55:357-362.

10. Guettier JM, Kam A, Chang R, Skarulis MC, Cochran C, Alexander HR, et al. Localization of insulinomas to regions of the pancreas by intraarterial calcium stimulation: the NIH experience. J Clin Endocrinol Metab 2009;94:1074-1080.

11. Thompson SM, Vella A, Service FJ, Grant CS, Thompson GB, Andrews JC. Impact of variant pancreatic arterial anatomy and overlap in regional perfusion on the interpretation of selective arterial calcium stimulation with hepatic venous sampling for preoperative localization of occult insulinoma. Surgery 2015; 158:162-172.

12. Placzkowski KA, Vella A, Thompson GB, Grant CS, Reading $\mathrm{CC}$, Charboneau JW, et al. Secular trends in the presentation and management of functioning insulinoma at the Mayo Clinic, 1987-2007. J Clin Endocrinol Metab 2009;94:1069-1073.

13. Doppman JL, Miller DL, Chang R, Gorden P, Eastman RC, Norton JA. Intraarterial calcium stimulation test for detection of insulinomas. World J Surg 1993;17:439-443.

14. Doppman JL, Chang R, Fraker DL, Norton JA, Alexander HR, Miller DL, et al. Localization of insulinomas to regions of the pancreas by intra-arterial stimulation with calcium. Ann Intern Med 1995;123:269-273.

15. Mehrabi A, Fischer L, Hafezi M, Dirlewanger A, Grenacher L, 
Diener MK, et al. A systematic review of localization, surgical treatment options, and outcome of insulinoma. Pancreas 2014; 43:675-686.

16. Shin JJ, Gorden P, Libutti SK. Insulinoma: pathophysiology, lo- calization and management. Future Oncol 2010;6:229-237.

17. Service FJ, McMahon MM, O'Brien PC, Ballard DJ. Functioning insulinoma--incidence, recurrence, and long-term survival of patients: a 60-year study. Mayo Clin Proc 1991;66:711-719. 